\title{
Малоизученные эндемики Западного Тянь-Шаня во флоре Сайрам-Угамского национального парка (Казахстан)
}

\section{Little-studied endemics of the Western Tien Shan in the flora of the Sairam-Ugam national park (Kazakhstan)}

\author{
Иващенко А. А. \\ Ivashchenko A. A. \\ Ассочиаџия сохранения биологического разнообразия Казахстана, г. Алматы, Казахстан. \\ E-mail:karime_58@mail.ru \\ Association for the Conservation of Biodiversity of Kazakhstan (ACBK), Almaty, Kazakhstan
}

\begin{abstract}
Peфepam. В статье приводятся данные о распространении и численности популяций четырех редких эндемиков (Jипо pseudocapnoides Ruksans, Arabis tianschanica Pavl., Autumnalia botschantzevii M. Pimen., Pseuderemostachys sewerzowii (Herd.) М. Рор.) в Сайрам-Угамском национальном парке, а также о 33 флористических новинках для хребтов Угамского и Каржантау в пределах Казахстана.
\end{abstract}

Ключевые слова. Возрастной спектр, плотность вида, популяция, растительное сообщество, флора, эндемичный вид.

Summary. Data on the distribution and population of four rare endemics (Juno pseudocapnoides Ruksans, Arabis tianschanica Pavl., Autumnali abotschantzevii M.Pimen., Pseuderemostachys sewerzowii (Herd.) M.Pop.) in the SairamUgam National Park, as well as 33 floristic novelties for Ugam and Karzhantau mountains ridges within Kazakhstan are given in the article.

Key words. Age spectrum, endemic species, flora, population, plant community, species density.

Сайрам-Угамский государственный национальный природный парк, учрежденный в 2006 г., занимает площадь 149053 га в горах Западного Тянь-Шаня (хребты Угамский, Каржантау и западная часть Таласского Алатау и Боролдайтау). Флора этой территории недостаточно изучена, особенно в пределах хр. Угамского и Каржантау, вплотную прилегающих к территории Узбекистана. Автор проводила флористические исследования на этой территории с начала 80-х гг. XX в. во время работы в заповеднике «Аксу-Жабаглы». Отдельные краткосрочные выезды проводились вплоть до весны 2018 г. Наиболее подробные исследования удалось провести автору в 2001-2003 гг. благодаря участию в качестве эксперта-флориста в разработке трансграничного проекта по сохранению биологического разнообразия Западного Тянь-Шаня, когда в результате детального обследования всей казахстанской части Западного Тянь-Шаня были разработаны естественно-научные обоснования для расширения территории заповедника «Аксу-Жабаглы», создания Каратауского заповедника и Сайрам-Угамского национального природного парка. Данные о самых интересных флористических находках были опубликованы (Иващенко, 2001; 2017; Иващенко и др., 2006). В настоящем сообщении излагаем сведения о малоизученных видах эндемичных растений и флористических новинках, не опубликованные ранее. Номенклатура видов дана по сводкам С. К. Черепанова (1995) и С. А. Абдулиной (1999).

Juno pseudocapnoides Ruksans (сем. Iridaceae) - новый вид для флоры Кахахстана, описанный с yp. Чимган, обитающий в нижнем и среднем поясах гор Западного Тянь-Шаня (Ruksans, 2007; Тожибаев и др., 2015). Во «Флоре Казахстана» (Павлов, Поляков, 1958) этот вид приводился для Угамского 
хребта под названием Juno magnifica Vved. Позже выяснилось, что он встречается только в Памиро-Алае (Введенский, 1971), поэтому был исключен из списка флоры Казахстана (Абдулина, 1999). Мы нашли его в 15 точках хр. Каржантау - в долинах рек Угам, Бадам, а также в ущельях северо-восточного склона хребта, от Донгустау до Каржан. Везде встречается изреженными микропопуляциями, численностью в несколько десятков особей, занимающими участки площадью от 10 до $50 \mathrm{~m}^{2}$. Средняя плот-

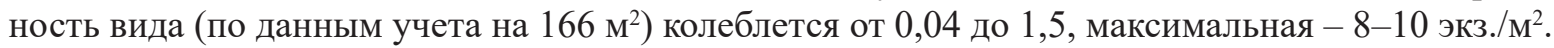

Juno pseudocapnoides встречается в составе трех типов растительности (по терминологии Р. В. Камелина (1990) - скал и осыпей; шибляка; изреженных арчевников, в интервале высот 1140-1850 м над ур. м. Общий флористический состав таких участков (по данным наших 15 описаний) составляет182 вида из 134 родов и 50 семейств. В десятку ведущих семейств (Rosaceae, Poaceae, Fabaceae, Lamiaceae, Caryophyllaceae, Asteraceae, Apiaceae, Liliaceae, Alliaceae) входит 61,5 \% от всего количества зарегистрированных видов. Флористическое богатство различных участков колеблется от 16-18 видов (скалистые склоны и осыпи в долинах рек Бадам и Наут) до 49-51 (изреженные арчевники и заросли кустарников в средних частях долин рек Наут и Угам), составляя в среднем 36 видов.

Наиболее частыми спутниками юноны (встречаемость более 30 \%) являются 22 вида: Juniperus seravschanica Kom., Cerasus tianschanica Pojark., Ephedra equisetina Bunge, Anisantha tectorum (L.) Nevski, Poa bulbosa L., Allium karataviense Regel, Ferula samarkandica Korov., Rhamnus coriacea (Regel) Kom., Eremurus lactiflorus O. Fedtsch.., Leymus aemulans (Nevski) Tzvel. и др. Два последних вида - эндемики Западного Тянь-Шаня, включая Каратау. Из 14 видов, преобладающих по обилию, еще 5 эндемов такого же ранга - Allium eriocoleaum Vved. ex Kaschtsch. et E. Nikit., Amygdalus petunnikovii Litv., Hedysarum pskemense M. Pop. ex B. Fedtsch., Cousinia tianschanica Kult., Olgaea pectinata Iljin. В целом доля западно-тяньшанских эндемиков в описанных сообществах составляет $13 \%$, количество редких видов, занесенных в Красную книгу Казахстана (2014) - 11 (Tulipa greigii Regel., T. kaufmanniana Regel, Ungernia sewerzowii B.Fedtsch., Clypeola jonthlaspi L., Pseuderemostachys sewerzowii (Herd.) M. Pop., Arum korolkowii Regel, Celtis caucasica Willd., Sorbus persica Hedl., Euonymus koopmannii Lauche, Malus sieversii (Ledeb.) M. Roem., Juniperus seravschanica Kom. Это свидетельствует в пользу необходимости особой охраны в Казахстане не только Juno pseudocapnoides как редкого регионального эндемика, но и растительных сообществ с его участием.

Поскольку указанный вид изучен недостаточно, считаем необходимым привести некоторые показатели морфологической характеристики генеративных особей. Высота стебля колеблется в пределах 22-30 см, длина нижнего листа 15-21,5 см, верхнего 6,5-17 см; ширина соответственно 1,2-3 см и 0,81,8 см. Количество листьев от 5 до 9, цветков от 1 до 8. Доля особей с 2-5 цветками, как приводится в описаниях (Ruksans, 2007; Тожибаев и др., 2015), по нашим данным, составляет всего 60 \%, значительна (25\%) доля особей с 1 цветком, меньше $(9 \%)$ - с 6, реже встречаются особи с 7 и 8 цветками (по 3 \%). Длина плода колеблется в пределах 2,5 -3,8 см, ширина 0,5-1 см; количество нормально развитых семян от 7 до 28.

Однако, несмотря на относительно высокую семенную продуктивность, Juno pseudocapnoides характеризуется низкой интенсивностью семенного размножения. В результате учетов 2003 г. нам не удалось найти ни проростков, ни ювенильных экземпляров. Обобщенный возрастной спектр популяции выглядит так: имматурные особи - 6,1 \%; виргинильные - $12,1 \%$; генеративные - 81,8 \%. Следовательно, в казахстанской части ареала, на его северной границе, состояние популяции исследуемого вида нельзя считать благоприятным из-за очень низких показателей возобновления. В связи с этим очевидна необходимость включения его в Красную книгу и установления регулярного контроля за состоянием популяций.

Arabis tianschanica Pavl. - эндемик Западного Тянь-Шаня, распространение которого изучено еще недостаточно. Во «Флоре Казахстана» (1962) он приводится только для Пскемского хребта - территории, которая находится сейчас в пределах Узбекистана. Видимо, поэтому он не числится в списке С. А. Абдулиной (1999).

Нами обследована единственная популяция на северном склоне левого берега верховий р. Бадам, в интервале высот 2175-2530 м над ур. м. Она разделена на отдельные изолированные фрагменты, 
занимающие участки различной площади от $25 \mathrm{~m}^{2}$ до 150-500 м². Соответственно различно и количество особей A. tianschanica - от 6-10 до 100-150, реже 400-500 экз.

A. tianschanica растет как на довольно крутых (до $30^{\circ}$ ), так и на выровненных участках склона, а также по неглубоким ложбинам. Поверхность почвы ощебненная, иногда с выходами небольших скал. Тип растительности - субальпийские луга, в составе которых доминирует разнотравье (Geranium saxatile Kar. et Kir., Nepeta mariae Regel, Lindelophia tschimganica (Lipsky) M. Pop. ex Pazij, Galatella chromopappus Novopokr., Jurinea capusii Franch., Cousinia chrysantha Kult., Lagostis korolkowii (Regel et Schmalh.) Maxim., Ranunculus paucidentatus Schrenk), реже - эфемероиды (Tulipa dasystemonoides Vved., Gagea caelestis Levichev, G.pseudomonutiflora Levichev). Количественное соотношение перечисленных видов меняется на различных участках. Общий флористический состав по 5 описаниям представлен 74 видами из 62 родов и 27 семейств, среди которых ведущее место занимают Asteraceae, Fabaceae, Lamiaceae.

Интересно, что четверть флоры сообществ с участием A.tianschanica составляют эндемики Западного Тянь-Шаня, еще столько же субэндемики, распространенные в Западном Тянь-Шане и Памиро-Алае, остальные - виды с более широким ареалом. Среди 10 наиболее часто сопутствующих видов доля узкоареальных видов еще более высока: три вида (Cousinia chrysantha, Jurinea capusii, Tulipa dasystemoides) - западнотяньшанские, четыре (Nepeta mariae, Lagotis korolkowii, Lindelophia tschimganica, Scuterllaria cordifrons Juz.) - западнотяньшанско-памироалайские, ареалы еще трех (Geranium saxatile, Aulacospermum simplex Rupr., Ranunculus paucidentatus Schrenk) выходят за пределы горной Средней Азии. Общая численность Arabis tianschanica в обследованной популяции составляет по примерным подсчетам не менее 1400-1600 особей, плотность колеблется в пределах 1-13 экз./ $\mathrm{M}^{2}$, средняя на отдельных участках 3,6-7 экз./ $\mathrm{M}^{2}$.

Arabis tianschanica - многолетнее рыхлодерновинное растения. Мощно развитые экземпляры имеют от 1 до 25, в среднем 9,7 генеративных побега; количество цветков на каждом из них колеблется в пределах 1-6 (среднее -4,2).

Autumnalia botschantzevii M.Pimen. - представитель битипного горносреднеазиатского эндемичного рода, описанного М. Г. Пименовым (1989) из Сырдарьинского Каратау и Нуратау. Он отличается необычным типом сезонного развития - ранневесенней вегетацией листовой розетки и позднелетним развитием генеративного побега. М. Г. Пименов (1989), ссылаясь на указания европейских ботаников, подчеркивает: «Растения с таким ритмом ... встречаются в аридных районах Древнего Средиземья в разных семействах, но в целом представляют собой довольно редкий феномен». Во флоре Казахстана представлен еще только один вид с подобным феноритмотипом - Ungernia sewerzowii (Regel.) B.Fedtsch. из сем. Amaryllidaceae.

Единственная найденная нами в хребте Каржантау популяция Autumnalia botschantzevii (Иващенко, 2001) была обследована 25 июля 1997 г. и 21 мая 2003 г. Она расположена в невысокой срединной части хр. Каржантау, на западном склоне правобережья р. Донгустау (1190-1300 над ур. м.). Этот участок в верхней части граничит с крутым гребнем известняковых скал, редкими кустарниками и зарослями Ferula ugamica Korov., в нижней - разнотравно-злаковым эфемеретумом, сильно засоренным синеголовником (Eryngium caucasicum Trautv.). С запада данный участок переходит в крутой щебнистый южный микросклон с изреженными зарослями Amygdalis spinosissima Bunge и разнотравно-пырейным (Elytrigia trichophora (Link.) Nevsk.) травостоем, а с востока - в неглубокую сухую ложбину с зарослями Crataegus turkestanica Pojark.

Популяция Autumnalia botschantzevii занимает пологий, около $15^{\circ}$ крутизной, участок площадью около 2 га с ощебненной (до 30-40 \%) почвой и отдельными крупными глыбами известняка до 70 см высотой. Растительный покров довольно густой - общее проективное покрытие составляет 90-95 \%. Он представляет собой производный фрагмент крупнотравных горных полусаванн с участием элементов других флороценотипов по терминологии Р. В. Камелина (1979) - шибляка, эфемеретума и степных кустарников. Большинство ассоциаций фрагментов сообщества с участием Autumnalia botschantzevii классифицируется как шиповниково-разнотравно-злаковые, в одном случае вместо шиповника и других кустарников доминирует миндаль (Amygdalus spinosissima Bunge). В целом флористический состав 
обследованного участка представлен 114 видами из 90 родов и 37 семейств. Пять ведущих семейств (Rosaceae, Asteraceae, Poaceae, Fabaceae, Lamiaceae) включают более половины от всей флоры. Более $20 \%$ ее составляют эндемичные (западнотяньшанские) и субэндемичные (западнотяньшанско-памироалайские) виды. Интересно, что кроме Autumnalia botschantzevii, считавшейся эндемиком Сырдарьинского Каратау, в составе обследованных сообществ отмечены еще два вида с таким же типом ареала Euphorbia sewerzowii Herd. ex Prokh. и Sailvia trautvetteri Regel. Данные об этих флористических новинках для хр. Каржантау опубликованы нами ранее (Иващенко, Самойлова, 2000). В составе данного сообщества встречается также Ungernia sewerzowii, феноритмотип которой такой же, как и у аутумналии Бочанцева.

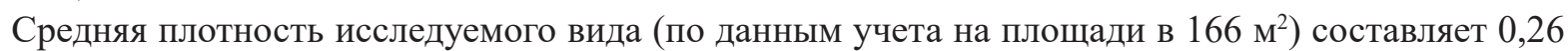

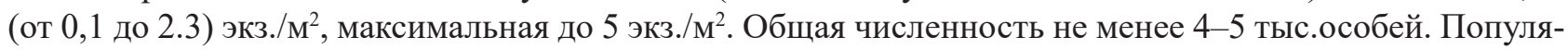
ция полночленная, в ней представлены особи всех возрастных состояний, причем доля вегетативных значительно выше $(61,7 \%)$, чем генеративных $(38,3 \%)$.

Относительно морфологических признаков вида, детально описанных М. Г. Пименовым (1989), можем добавить немногое. Генеративный побег 60-110 см высотой, трижды-четырежды ветвится до 3 -го порядка; центральный (осевой) зонтик обычно ниже боковых и состоит чаще всего (65 \%) из 9 лучей, реже (по 5-15 \%) из 6-8 или 10-11 лучей. Зонтики ветвей первого порядка 7-лучевые, второго и третьего порядков 5-лучевые. Раскрытые цветки в жаркий полдень 25 июля выделяли большое количество нектара.

Pseuderemostachys sewerzowii (Herd.) М. Рор. - представитель монотипного рода, широко распространенный в Каратау и западной части Таласского Алатапу, частично в Киргизском Алатау. В Каржантау известен из одной точки - горы Акбаштау (Определитель..., 1987). Нами обнаружена единственная микропопуляция на юго-западном каменистом склоне правобережья р. Наут (1600 м) в составе кустарниково-разнотравной ассоциации. Популяция состоит из нескольких изолированных групп общей численностью около 50 особей, доля генеративных - менее $10 \%$.

Флора описанного участка представлена 30 видами, треть из которых - западнотяньшанские и западнотяньшанско-памиро-алайские эндемики. Два из них (Olgaea pectinata, Cousinia tianschanica) встречаются в значительном обилии, остальные виды, за исключением Cerasus tianschanica, единично. Общее проективное покрытие растительности здесь не превышает 25-30 \%.

В результате инвентаризации флоры Сайрам-Угамского национального парка нами обнаружены здесь еще несколько десятков видов, которые не указаны для Каржантау и Угамского хребта в капитальной флористической сводке по Средней Азии (Определитель..., 1968-1993) и в других источниках (Кармышева, 1973; 1982; Иващенко, Самойлова, 2000). По типу ареала эти виды разделяются на четыре категории: 1 - эндемики Сыр-Дарьинского Каратау, в трактовке Р. В. Камелина (1990); 2 - эндемики Западного Тянь-Шаня, иногда заходящие в Каратау; 3 - эндемики Западного Тянь-Шаня и Памиро-Алая; 4 - широко распространенные виды.

К первой категории относится 3 вида.

Leymus aemulans (Nevski) Tzvel. - не указан для Каржантау (Цвелев, 1976; Камелин, 1990). Мы неоднократно отмечали его на сухих ощебненных склонах и осыпях в долине р. Наут (1600-1860 м).

Salvia trautvetteri Regel. Сведения о находке в Каржантау опубликованы нами ранее (Иващенко, Самойлова, 2000). Позже отмечено произрастание его в Угамском хребте - в низовьях р. Сазаната, правобережного притока р. Сайрамсу (1800 м).

Ligularia pavlovii (Lipsch.) Cretz. - редкий эндемик Каратау (Определитель..., 1993), хотя Р. В. Камелин (1990) считал возможным произрастание его в прилегающих регионах Западного Тянь-Шаня. Немногочисленные особи найдены нами, вместе с Л. К. Белоусовой, 14 июля 2003 г. на щебнисто-скалистых склонах верховий р. Бадам (Каржантау, 2400 м).

Из растений второй категории наиболее интересны находки в Каржантау (Каскасу, Наут, Бадам и др.) Astragalus asaphes Boriss., A.krauseanus Regel, A.nematodes Bunge, A.pachyrhizus M. Pop., Schrenkia congesta Korov., Seseli talassicum (Korov.) M. Pimen. et Sdobnina, Pedicularis talassica Vved., Asyneu- 
ma ramosum Pavl., Ligularia karataviensis (Lipsch.) Pojark., Olgaea pectinata Iljin, Pseudoglossanthis tianschanica (Krasch.) R. Kam., Echinops tschimganicus B.Fedtsch., а в Угамском хребте (верховья р.Сайрамсу, левобережье р.Угам) - Stephanocaryum olgae (B.Fedtsch.) M. Pop., Phlomoides tianschanicus (M.Pop.) Adyl., R. Kam. et Machmedov.

Из видов третьей категории новинками для Каржантау являются находки Astragalus subscaposus M. Pop. ex Boriss., Onobrychis echidna Lipsky, Ulugbekia tschimganica (B.Fedtsch.) Zak., Macrotomia ugamensis М. Рор.; для Угамского хребта - Aconitum talassicum M. Pop., Euphorbia sewerzowii Herd. ex Prokh., Ferula samarkandica Korov.

Из видов четвертой категории, с более широким ареалом, новинками для Каржантау являются Orthurus кокапісиs (Regel et Schmalh.) Juz., Astragalus dipelta Bunge, Scrophularia umbrosa Dumort., Carum carvi L., Onobrychis pulchella Schrenk; для Угамского хребта - Delphinium confusum M. Pop., Chalcanthus renifolius Boiss., Astragalus aksuensis Bunge, A.platyphyllus Kar. et Kir.

Все эти находки свидетельствуют о необходимости продолжения инвентаризации флоры казахстанской части Западного Тянь-Шаня, в том числе и территории Сайрам-Угамского национального парка.

Благодарности. Автор искренне признательна Р. В. Камелину, И. Г. Левичеву, А. Л. Эбелю, М. Г. Пименову, в разное время уточнивших таксономическую принадлежность гербарных образцов, а также коллегам по экспедициям - Е. И. Рачковской, К. М. Пачикину, Л. К. Белоусовой, Е. С. Чаликовой, Ю. А. Грачеву, Р. Т. Шаймарданову, О. В. Белялову, А. Х. Олонцовой, Р. Садвокасову, С. Темирбекову, и водителям - М. Абидкулову и Ю. Камзолову - за дружеское участие и помощь в маршрутах.

\section{ЛИТЕРАТУРА}

Абдулина $\boldsymbol{C}$. $\boldsymbol{A}$. Список редких растений Казахстана. - Алматы, 1999. - 187 с.

Введенский А. И. Род Јuno Tratt. // Определитель растений Средней Азии. - Ташкент: ФАН, 1971. - Т. 2. - С. 132-139.

Иващенко А. A. Флористические новинки Казахстанского Тянь-Шаня // Изучение растительного мира Казахстана и его охрана: Матер. 1-ой Молодежной ботан. конф., посвящ. 10-летию Независимости Республики Казахстан (г. Алматы, 1-2 марта 2001 г.). - Алматы, 2001. - С. 46-50.

Иващенко $\boldsymbol{A}$. $\boldsymbol{A}$. Новые и редкие виды флоры хребта Кызыгурт (Западный Тянь-Шань) // Изучение, сохранение и рациональное использование растительного мира Евразии: Междунар. науч. конф., посвящ. 85-летию Института ботаники и фитоинтродукции КН МОН РК (17-19 августа 2017 г., г. Алматы), 2017. - С. 218-223.

Иващенко А. А., Олонцева А. Х., Нелина Н. В. О некоторых редких и новых для Казахстана растениях Западного Тянь-Шаня // Матер. Междунар. науч.-практ. конф. «Актуальные проблемы экологии и природопользования в Казахстане и сопредельных территориях». - Павлодар, 2006. - С. 218-220.

Иващенко $\boldsymbol{A}$. А., Самойлова В. A. Дополнения к флоре хребта Каржантау // Известия Министерства образования и науки НАН РК. Серия биолог. и медиц. - 2000, №5. - С.9-13.

Камелин Р. В. Кухистанский округ горной Средней Азии. Ботанико-географический анализ. - Л.: Наука, 1979. $-117 \mathrm{c}$.

Камелин Р. В. Флора Сырдарьинского Каратау. - Л.: Наука, 1990. - 145 с.

Кармышева Н. X. Флора и растительность заповедника Аксу-Джабаглы. - Алма-Ата: Наука, 1973. - 180 с.

Кармышева Н. X. Флора и растительность западных отрогов Таласского Алатау. - Алма-Ата: Наука, 1982. $160 \mathrm{c}$.

Красная книга Казахстана. Т.2. Ч.1. Растения. - Астана, 2014. - С. 23, 115, 126, 143, 145, 198, 273, 353, 356, 384, 405.

Определитель растений Средней Азии. Тт.1-10. - Ташкент: ФАН, 1968-1993.

Павлов Н. В., Поляков П.П. Род Юнона - Јuno Tratt. // Флора Казахстана. - Алма-Ата: Изд-во АН КазССР, 1958. - T.2. - C. 247-252.

Пименов М. Г. Autumnalia M.Pimen. - новый эндемичный для Средней Азии род с двумя новыми видами // Бот .журн., 1989. - Т. 74, №10. - С. 1488-1495.

Тожибаев К. Ш., Бешко Н. Ю., Кадыров Р. У., Газиев А. Д. О Пьенг Ун, Чанг Ги Жанч, Шин Чвнг Хо, Чой Кьюнг. Флора Западного Тянь-Шаня. Горы Чимгана. - Почон, 2015. - 344 с. 
Флора Казахстана. Т. 5. - Алма-Ата, 1962. - С. 497-498.

Цвелев Н. Н. Злаки СССР. - Л.: Наука, 1976. - 788 с.

Черепанов $\boldsymbol{C}$. $\boldsymbol{K}$. Сосудистые растения России и сопредельных государств. - СПб: Изд-во «Мир и семья», 1995. - 999 c.

Ruksans J. Buried Treasures. - Portland, 2007. - 384 p. 